\title{
Relationship between performance on the Everyday Spatial Activities Test and on objective measures of spatial behavior in men and women
}

\author{
WILLIAM W. BEATTY \\ North Dakota State University, Fargo, North Dakota \\ and Neuropsychiatric Research Institute, Fargo, North Dakota \\ and \\ DEE DUNCAN \\ North Dakota State University, Fargo, North Dakota
}

\begin{abstract}
The validity of the Everyday Spatial Activities Test (ESAT) for predicting performance on tasks requiring visuosptial perception and knowledge was examined in a sample of male and female college students. ESAT scores were positively correlated with performance on tests of visuospatial perception but not with measures of visuospatial (geographic) knowledge. However, with the exception of performance on the water jar problem, demographic variables were better predictors of performance than the ESAT was, suggesting that the test may have limited utility.
\end{abstract}

Gender differences in spatial abilities have been widely documented (for review, see Linn \& Petersen, 1985), but the factors responsible for these differences remain unclear. One hypothesis holds that males excel on formal tests of spatial ability because they are more likely than females to engage in spatial activities in everyday life. Consistent with this idea are reports of positive correlations between performance on various tests of spatial ability and measures of experience with everyday activities that appear to possess a spatial component. Such findings have been reported for preschool children (Connor \& Serbin, 1977; Serbin \& Connor, 1979) and college students (Lunneborg \& Lunneborg, 1986a, 1986b; Newcombe, Bandura, \& Taylor, 1983).

In addition to their theoretical significance for understanding the origin of gender differences in spatial behavior, assessments of everyday spatial experiences may have practical value if it can be shown that such measures permit more accurate prediction of performance on laboratory spatial tasks and, more importantly, in real life activities such as engineering.

For this latter purpose, it is desirable that a test of spatial experience be brief and suitable for group administration. The Everyday Spatial Activities Test (ESAT) developed by Lunneborg and Lunneborg (1986b) fulfills these criteria, and, in addition, appears to possess adequate test-retest reliability (Luneborg \& Lunneborg, 1986a). Evidence of the predictive validity of the ESAT

Correspondence and reprint requests may be addressed to William $\mathbf{S}$. Beatty, Department of Psychology, North Dakota State University, Fargo, ND 58105. is limited. Preliminary studies indicate correlations ranging from 0.24 to 0.35 with performance on standardized tests such as the spatial relations subtest of the Differential Aptitude Test.

The purpose of the present study was to gather additional information regarding the predictive validity of the ESAT. Subjects received a battery of visuospatial tests, as well as the ESAT. As a measure of real world visuospatial knowledge, we employed the Fargo Map Test, a test of geographical knowledge (Beatty \& Tröster, 1987). On most of these measures, including the ESAT, gender differences have usually been observed.

\section{METHOD}

\section{Subjects}

The subjects were 59 male and 61 female undergraduate students at North Dakota State University. As compensation for their time, they received extra credit points that counted toward their grades in the introductory psychology courses in which they were enrolled. All subjects were born in the United States, and most were lifelong residents of North Dakota or Minnesota. Other demographic information is given in Table 1.

\section{Materials and Procedure}

In groups of 6-15, subjects completed the ESAT (Lunneborg \& Lunneborg, 1986b), the Mental Rotations Test (Vandenberg \& Kuse, 1978), the revised version of the Fargo Map Test (FMT-R) (Beatty, 1988), the New Map Test (Beatty \& Tröster, 1987), and the pathfinding test, a measure of egocentric spatial orientation (Beatty \& Tröster, 1987).

Each of the 20 items on the ESAT was scored on a 6-point scale $(0=$ no familiarity with the activity, $5=$ very good). Separate scores were derived for the handtools, science courses, arranging objects, and mechanical drawing subscales, by totaling scores on the relevant items. In addition, the total score was derived by summing scores on the four subscales. 
Table 1

Mean Performance, with Standard Deviations, on the Various Measures

\begin{tabular}{|c|c|c|c|c|c|}
\hline \multirow[b]{2}{*}{ Measure } & \multicolumn{2}{|c|}{ Males } & \multicolumn{2}{|c|}{ Females } & \multirow{2}{*}{$\begin{array}{r}F(1,118) \\
\text { for Gende }\end{array}$} \\
\hline & $M$ & $S D$ & $M$ & $S D$ & \\
\hline Age (years) & 21.9 & 3.8 & 24.0 & 7.6 & 3.72 \\
\hline Education (years) & 13.4 & 1.5 & 13.5 & 1.5 & 0.37 \\
\hline Pathfinding & 15.1 & 1.6 & 13.1 & 3.1 & $19.53 \ddagger$ \\
\hline Water jar & 6.0 & 3.2 & 4.2 & 3.4 & $8.63+$ \\
\hline Mental Rotations Test & 21.5 & 8.5 & 12.0 & 6.3 & $48.08 \ddagger$ \\
\hline New Map Test & 32.1 & 7.8 & 32.5 & 9.0 & 0.06 \\
\hline US gross features/10 & 9.5 & 0.9 & 8.8 & 1.6 & $8.78 \dagger$ \\
\hline US cities location/30 & 15.3 & 5.0 & 12.3 & 5.2 & $9.84 \dagger$ \\
\hline City state/30 & 27.5 & 2.6 & 26.8 & 3.5 & 1.42 \\
\hline Tristate cities location $/ 18$ & 11.8 & 3.0 & 9.6 & 3.2 & $15.50 \ddagger$ \\
\hline States visited $(N)$ & 15.4 & 9.7 & 17.0 & 9.8 & 0.77 \\
\hline Tristate cities visited $(N)$ & 10.2 & 3.6 & 10.2 & 2.8 & 0.00 \\
\hline \multicolumn{6}{|l|}{ ESAT } \\
\hline Handtools & 19.9 & 3.6 & 14.5 & 5.3 & $41.94 \ddagger$ \\
\hline Science courses & 17.9 & 3.9 & 15.3 & 4.3 & $12.15 \ddagger$ \\
\hline Arranging objects & 18.1 & 3.7 & 19.5 & 3.0 & $5.77^{*}$ \\
\hline Mechanical drawing & 16.2 & 4.7 & 12.0 & 5.7 & $19.93 \ddagger$ \\
\hline Total & 72.0 & 11.4 & 61.2 & 12.5 & $24.46 \ddagger$ \\
\hline
\end{tabular}

${ }^{*} p<.05 . \quad \dagger p<.01 . \quad \ddagger p<.001$.

The subjects were allowed $6 \mathrm{~min}$ to complete the 20 items on the Mental Rotations Test. They were told that for each item there were two correct and two incorrect answers. On a particular item, the subjects received two points if they marked both correct choices and one point if they marked only one correct choice. All other responses received a score of 0 for the item. The maximum possible was 40 .

For the pathfinding test, the subjects were shown a slide with the points labeled "Begin" and "End" connected by a line that contained 16 right angle turns. The subjects were asked to imagine that they were walking a route from "Begin" to "End" and to indicate whether they would turn to the left or to the right at each turn. Five seconds were allowed for each response.

A paper-and-pencil version of the water jar problem was used. The subjects were first shown an outline drawing of a jar capped with a cork resting cork-side-up on a horizontal line that was identified as a "table." They were told that the jar was half-full of water, as indicated by the horizontal line (the "water-line") parallel to the "table." They were told that on the following pages the jar would be shown in various orientations, and that they were to draw, using the pencil and straightedge provided, the "water-line" as it should appear. The jar was shown in 8 different orientations $(1,2,4,5,7,8,10$, and 11 o'clock), which were arranged in a random order. Each item was scored as correct (subject's line within $4^{\circ}$ of horizontal) or incorrect. The height of the waterline was not considered in the scoring. The maximum score was 8.

The New Map Test requires subjects to learn the locations of places on an unfamiliar map. First, the subjects were shown an outline map consisting of three contiguous "states." Within these states were 15 hypothetical "towns." After an explanation of the task, the subjects studied the map for $60 \mathrm{sec}$. Then they were given a test map, which consisted of an outline map of the three states with 25 numbered dots and the names of the 15 towns printed above the map. The subjects indicated the location of each town by writing the number of the dot that corresponded to the location of each town in the space after its name. Three such study-recall trials were given. The dependent variable was the total number of towns located exactly over the three trials combined.

The FMT-R requires subjects to locate 10 gross features of U.S. geography (e.g., the Atlantic Ocean) and 30 U.S. cities on an outline map of the U.S. As a verbal measure of geographical knowledge, the subjects also indicated in which state each of the 30 cities is located (termed "city state").

As a measure of knowledge of the geography of the local region, the subjects attempted to locate 18 cities on an outline map of the tristate region (ND, SD, MN). To provide measures of travel history, the sub- jects also indicated which of the $\mathbf{4 8}$ continental states and which of the 18 tristate cities they had visited or traveled through on surface transportation.

\section{RESULTS}

Table 1 summarizes average performance for males and females. Here it can be seen that the expected gender differences on the pathfinding task, the Mental Rotations Test, the water jar problem, and the three visuospatial measures of geographical knowledge (i.e., locating gross features of US geography, US cities, and tristate cities) were observed.

Significant gender differences were also observed on all scales of the ESAT. The male subjects attained higher scores on the handtools, science courses, and mechanical drawing scales, whereas the female subjects scored higher on the arranging objects scale.

Table 2 summarizes correlations for men and women among the various ESAT scales and the measures of visuospatial performance. Of the three measures of visuospatial perception, only the water jar problem was consistently correlated with the ESAT for both male and female subjects. Weak positive correlations between the ESAT total and performance on the Mental Rotations Test and between the ESAT total and scores on the pathfinding test were observed for women only.

Performance on the ESAT was positively correlated with new map learning for female, but not for male subjects. A similar but more extreme difference in the pattern of correlations for men and women was observed for locating US cities. For women, performance on this measure was positively correlated with ESAT total scores, whereas for men, this relationship was reversed. For other measures of geographical knowledge, low correlations with the ESAT scores were observed for both genders.

The predictive validity of the ESAT was also studied with stepwise multiple regression analyses, to determine

Table 2

Correlations Among ESAT Scales and Visuospatial Measures

\begin{tabular}{lcllrrrr}
\hline & PF & WJ & MR & NM & USG & USC & TSC \\
\hline HT & -00 & $41^{*}$ & 04 & -16 & -02 & $-32^{*}$ & 06 \\
SCI & 12 & $37^{*}$ & 11 & -02 & 07 & -19 & 06 \\
OBJ & 03 & 18 & 22 & -05 & -03 & -05 & -11 \\
MEC & 10 & $40^{*}$ & 25 & 01 & 00 & -24 & -08 \\
TOT & 08 & $48^{*}$ & 23 & -07 & 01 & $-28^{*}$ & -03 \\
& \multicolumn{7}{c}{ Male } \\
HT & 14 & 21 & 05 & 11 & -10 & 14 & 11 \\
SCI & $28^{*}$ & $28^{*}$ & $32^{*}$ & $44^{*}$ & 23 & $32^{*}$ & 16 \\
OBJ & 10 & 02 & 09 & 21 & 01 & 12 & 15 \\
MEC & 21 & $27^{*}$ & 19 & $29 *$ & 10 & 17 & 07 \\
TOT & $28 *$ & $32^{*}$ & 24 & $38^{*}$ & 08 & $27^{*}$ & 17 \\
\hline
\end{tabular}

Note-Decimal points are omitted. *Correlations of .26 or greater, which are significant at the .05 level. $\mathrm{PF}=$ pathfinding, $\mathrm{WJ}=$ water jar, MR = Mental Rotations Test, NM = New Map Test, USG = locating gross feature of US geography, USC = locating US cities, TSC = locating tristate cities, $\mathrm{HT}=$ handtools, $\mathrm{SCI}=$ science courses, $\mathrm{OBJ}=$ arranging objects, and MEC $=$ mechanical drawing. TOT $=$ total. 
Table 3

Summary of Multiple Regression Analyses

\begin{tabular}{|c|c|c|c|c|}
\hline Dependent Variable & Best Predictor & $R^{2}$ & $\begin{array}{l}\text { Other Significant } \\
\text { Predictors }\end{array}$ & $R^{2}$ \\
\hline Pathfinding & Gender & .14 & ESAT science & .21 \\
\hline Water jar & ESAT total & .20 & $\begin{array}{l}\text { Years education, } \\
\text { ESAT ar obj }\end{array}$ & .28 \\
\hline Mental rotation & Gender & .29 & ESAT total, age & .36 \\
\hline New map & ESAT sci & .05 & Years education & .10 \\
\hline US gross features & Gender & .07 & States traveled & .12 \\
\hline US cities location & Gender & .08 & $\begin{array}{l}\text { Years education, } \\
\text { states traveled }\end{array}$ & .18 \\
\hline $\begin{array}{l}\text { Tristate cities } \\
\text { location }\end{array}$ & $\begin{array}{l}\text { Tristate cities } \\
\text { visited }\end{array}$ & .12 & Gender, Age & .27 \\
\hline
\end{tabular}

Note $-R^{2}$ is shown for the best predictor alone and for all significant predictors combined (right-hand column).

which variables accounted for significant variance on the various visuospatial measures. Table 3 summarizes the results of these analyses. For each visuospatial measure, the proportion of variance $\left(R^{2}\right)$ accounted for by the single best predictor and for all variables contributing significantly to the accuracy of prediction is reported. Of the seven dependent variables, scores on the ESAT were the best predictor for two, accounting for $20 \%$ of the variance on the water jar problem and $5 \%$ of the variance on the New Map Test. ESAT scores increased the accuracy of prediction for two other variables (pathfinding, mental rotation), but gender alone was the best predictor on both measures. Only the demographic measures age, gender, and travel history contributed significantly to the prediction of geographical knowledge.

\section{DISCUSSION}

In the present study, the expected gender differences were observed on visuospatial measures of perception (Linn \& Petersen, 1985) and geographical knowledge (Beatty \& Tröster, 1987). In agreement with earlier work (Lunneborg \& Lunneborg, 1986a, 1986b), males attained higher overall scores on the ESAT because of their higher scores on the handtools, science courses, and mechanical drawing scales. In our study, women achieved significantly higher scores on the arranging ob- jects scale; in earlier studies (Lunneborg \& Lunneborg, 1986a, 1986b), a similar nonsignificant trend was observed on this measure.

With the exception of the pathfinding test for males, moderate positive correlations between the total score on the ESAT and measures of visuospatial perception were observed in the present study. Since the low correlation between scores on the pathfinding test and the ESAT for males may have arisen because of a ceiling effect, our findings are in agreement with earlier reports (Lunneborg \& Lunneborg, 1986a, 1986b), indicating limited validity for the ESAT in predicting performance on laboratory spatial tasks.

At the same time, the present data raise doubts about the overall usefulness of the ESAT for predicting spatial behavior. Except for the water jar problem, easily obtained demographic variables were better predictors on most measures of visuospatial perception and knowledge than the ESAT was.

\section{REFERENCES}

Beatty, W. W. (1988). The Fargo Map Test: A standardized method of assessing remote memory for visuospatial information. Journal of Clinical Psychology, 44, 61-67.

BeAtTy, W. W., \& Tröster, A. I. (1987). Gender differences in geographical knowledge. Sex Roles, 16, 565-590.

Connor, J. M., \& SerBin, L. A. (1977). Behaviorally based masculineand feminine-activity preference scales for preschoolers: Correlates with other classroom behaviors and cognitive tests. Child Development, 48, 1411-1416.

LinN, M. C., \& Peterson, A. C. (1985). Emergence and characterization of sex differences in spatial ability: A meta-analysis. Child Development, 56, 1470-1498.

LunNeborg, P. W., \& Lunneborg, C. E. (1986a, August). Correlates with Everyday Spatial Activities Test scores for the sexes. Paper presented at the Annual Meeting of the American Psychological Association, Washington, DC.

LUNNEBORG, P. W., \& LUNNEBorg, C. E. (1986b). Everyday Spatial Activities Test for studying differential spatial experience and vocational behavior. Journal of Vocational Behavior, 28, 135-141.

Newcombe, N., BANDURA, M. M., \& TAYLOR, D. G. (1983). Sex differences in spatial ability and spatial activities. Sex Roles, 9, 377-386.

SERBIN, L. A., \& ConNor, J. M. (1979). Sex-typing of children's play preferences and patterns of cognitive performance. Journal of Genetic Psychology, 134, 315-316.

VANDENBERG, S. G., \& KUSE, A. R. (1978). Mental rotations: A group test of three-dimensional spatial visualization. Perceptual \& Motor Skills, 47, 599-604.

(Manuscript received July 29, 1989.) 